\title{
EFL Teachers' Awareness of Dyslexia in Algerian Middle Schools
}

\author{
Miloud Fekih \\ Affiliation: The West of Scotland University- United Kingdom
}

\begin{abstract}
In this study, Algerian EFL (English as a Foreign Language) teachers' awareness of, and familiarity with, dyslexia was explored to understand their perspectives on learners with the condition. A purposive sample of 42 EFL teachers from all over Algeria (North, South, West and, East) was surveyed, starting with a web-based questionnaire that addressed teachers' awareness and knowledge about reading difficulties. Semi-structured interviews were then conducted with 15 EFL teachers in order to dig deeply into teachers' understanding and comprehension, followed by two focus group discussions conducted with 8 teachers for more understanding. Findings revealed that the overwhelming majority of Algerian EFL teachers in this sample are not aware of dyslexia but instead linked it to other disabilities. In addition to that, participants' answers demonstrated that because of their poor knowledge of dyslexia they misconceive affected learners and see them as lazy, stupid and or incapable to learn. Overall, the study revealed that awareness and acquaintance among EFL Middle school teachers in Algeria are poor in relation to dyslexia. Thus, it is recommended that all teachers need to have compulsory training programs that stress the understanding of learning disabilities especially dyslexia and the importance of accommodating learners' needs.
\end{abstract}

Keywords: dyslexia, awareness, understanding, Algerian EFL teachers, attitudes.

\section{1- Introduction:}

Teachers, in general, have to deal with diverse kinds of learners and be acquainted with their needs. There are many learners who encounter challenges as a result of special needs; therefore they might experience more difficulties in learning and being successful. Education is of paramount significance in our life where all children ought to have the same chance to receive the same education without making any differentiation between them in terms of ability. However, Chong et al. (2007) claimed that inclusive education does not only signify teaching learners with particular needs together with their classmates, in fact, it means teaching through the use of suitable pedagogy to meet the needs of those with learning difficulties. Campbell et al. (2003) point out that teachers' awareness of learning needs is very important to create inclusive classes as well as it may change teachers' attitudes to be more positive toward those who struggle form different difficulties. 
Hence, teachers' awareness can be raised around the realization, acquaintance and or the comprehension of the disability/difficulty so the teacher can be knowledgeable in accommodating the learners' special needs. Endsley (1995, p.36) offers a useful definition of 'situation awareness' which can be applied to the classroom context where a teacher encounters a learner with dyslexia. 'Awareness' in this situation is defined as '. . . the perception of the elements in the environment, ...the comprehension of their meaning, and the projection of their status in the near future'. In the same fashion, Menon, (2016, p. 79) defines awareness as "having knowledge of something / realizing something and also as interested in and knowing about something". Therefore, teacher awareness of dyslexia is very important to the success of affected children because, according to Karande et al. (2009), many learners with reading difficulties report high levels of anxiety and fear for the reason that, their teachers have a poor understanding and insufficient awareness of dyslexia.

Consequently, the importance of conducting this study is that numerous academic investigations have been conducted in different countries on the subject of weighing up teachers' awareness of dyslexia (Wadlington \& Wadlington, 2005 and Knight, C., 2018). I found no similar studies pertaining to the Algerian context. Hence, and since teachers' understanding and awareness of reading impairment are essential as mentioned above for inclusive education and meeting learners' needs, then I believe that this project will support the educational system in Algeria and shed light on dyslexia and other related difficulties by first, evaluating Algerian EFL teachers' awareness toward reading difficulties in Middle schools and seeking potential reasons for the lack of awareness, and secondly, coming up with suitable suggestions for raising awareness in Middle School Algerian teachers.

\section{2- Literature Review}

Dyslexia could be a bewildering term for many teachers because frequently teachers are uncertain about its meaning and characteristics, where commonly they struggle to differentiate between students with dyslexia and poor readers (Wadlington, Jacob \& Bailey, 1996). This confusion around dyslexia may go back to the absence of a universal definition.

\section{2-1 Dyslexia's definitions}

There are a lot of different definitions of reading difficulties since the emergence of the difficulty; however, giving an exact meaning to dyslexia still remains a challenge for scholars, experts, and specialists. Some definitions stressed the neurological origins of dyslexia, for instance, the International Dyslexia Association (IDA) (2002) defined it as "a specific learning disability that is neurological in origin. It is characterized by difficulties with accurate and/or fluent word recognition, and by poor spelling and decoding abilities"(cited in Nicolson, and Fawcett, 2010, p.11). In the same way, and according to the Orton Society (1994) "dyslexia is a neurologicallybased, often familial, disorder which interferes with the acquisition and processing of the language". (cited in Gilchrist, 1997, p.5). Other definitions prefer to focus on dyslexia's indicators, for example, The World Federation of Neurology (1968) refer it 
to "a difficulty in learning to read, write or spell, despite conventional instruction, adequate intelligence, and socio-cultural opportunity" (Pumfrey and Reason, 2013, p.14).

In addition to that, other definitions integrate instructional methods "it is often unexpected in relation to other cognitive abilities and the provision of effective classroom instruction" (Lyon, Shaywitz \& Shaywitz, 2003, p. 2). Furthermore, some scholars refer to dyslexia to be a disability that hampers individuals despite the classroom environment and adequate intelligence. Miles (1985, p.41) claimed that dyslexia "is a disorder in children who, despite conventional classroom experience, fail to attain the language skills of reading, writing, and spelling, commensurate with their intellectual abilities". Other definitions stressed the biological reasons and the heritability where we can find Frith, 1999, (p. 192) who defined dyslexia as "a neurodevelopmental disorder with a biological origin". While many researchers agree that dyslexia occurs because of neurological and biological factors that cause the presented consequences, others believe that it is only a trouble when the teachers are not aware of dyslexia. In this regard, Buckler and Castle (2014) claimed that dyslexia has not been seen as a difficulty; it is only an impediment and trouble if the teacher is not aware of it and unable to utilize appropriate methods and techniques that suit learners' needs.

The different definitions of dyslexia can be a reason for it being difficult to be understood and or be confused with other reading difficulties. There is a need for a universal definition, if only for the purpose of making from dyslexia a clear difficulty for everyone especially teachers. For the purpose of this paper dyslexia is understood as

\begin{abstract}
Reading disability is a reading and language-based learning disability, also commonly called dyslexia. For most children with learning disabilities receiving special education services, the primary area of difficulty is reading. People with reading disabilities often have problems recognizing words that they already know. They may also be poor spellers and may have problems with decoding skills. Other symptoms may include the trouble with handwriting and problems understanding what they read.
\end{abstract}

(Christo. et al. p. 6).

I have chosen this definition for use in this paper as it contextualizes dyslexia within an educational setting rather than focusing on biological or neurological issues. It is in the classroom that my participants encounter dyslexia and so this definition is more suited to the study rather than a medical or pathological definition.

\title{
2-1-1 Dyslexia's Characteristics
}

Individuals with dyslexia might exhibit different traits and behaviours which, according to Townend and Turner (2002), can be signs for teachers as well. These 
characteristics can be different from one individual to another. However and according to American Academy of Pediatrics (2009) and Shaywitz, and Shaywitz, (2013) most affected people display difficulties in the following areas: word retrieval, rapid naming, spelling, processing information, reading, speech, organisation, coordination, short-term memory. However these are not all the characteristics of dyslexia but only the most common ones.

There are different degrees of dyslexia that vary from mild to severe. In addition to that, it is very significant to bear in mind that those with dyslexia are not unmotivated people or unintelligent. In fact and according to Bartlett, et al (2010) those with dyslexia usually are average to above average in intelligence, gifted and multitalented.

\section{2-2 Dyslexia and teachers' unawareness and misunderstanding}

In previously undertaken research, many researchers found that misunderstanding of an individual with dyslexia might lead teachers to think negatively about those who are struggling with reading difficulties. Kenny et al. (2003), for example, claimed that for the most part individuals with reading impairment might be seen to be sluggish or unintelligent where they may not receive sufficient support and help from their teachers in the classrooms because of unawareness and misunderstanding about dyslexia. In addition to that, people with dyslexia as a result of teachers' misunderstanding might suffer from low self-esteem (Gibson \& Kendall, 2010); be alienated, marginalized, and humiliated; they might feel as if they are an outsider in their own classroom and unable to cope with their colleagues (Townend \& Turner, 2002).

Furthermore, Wadlington and Wadlington (2005) point out that teachers often have mistaken beliefs about reading difficulties. Their study revealed that because of unawareness and poor knowledge of the condition, there are negative attitudes toward those with dyslexia in school. In turn, and as a result of teachers' lack of understanding of dyslexia and belated intervention, the affected learners can develop further problems where the situation can be even worse (Wadlington and Wadlington 2005). As a kind of miscomprehension of learning disabilities in general, teachers still believe that the learner's underachievement is either because of a lack of cleverness and or sluggishness (Wormald, 2015). Other teachers and even parents think that the student's lack of accomplishment is because of his or her lack of motivation and laziness (Smart, 2011). According to Fekih (2018) EFL teachers in Algeria lack the awareness needed to teach struggling readers where he stresses the need for raising teachers' consciousness of dyslexia. This kind of lack of knowledge and awareness might well be disadvantageous to the academic success of those with educational special needs. The negative attitudes do not stop at the level of seeing them as unmotivated students, with others viewing such students as "Class Clowns" and embarrassing them because of their underachievement (Smart, 2011 p.290). In the same manner Fekih claimed that as a result of unawareness "those with dyslexia will continue to encounter difficulties in reading where their academic progress may be negatively affected" (2018, p13). 
According to Elias (2014), teacher knowledge and awareness of dyslexia are of paramount significance in understanding the learners' needs, having positive attitudes toward affected learners and helping them overcoming their difficulties as well as improving their attainment levels. Contrary to that, a research investigation carried out by the Ministry of Education in Japan showed that teachers were not even aware if their learners are struggling with particular learning difficulties or not (Kataoka et al., 2004). In the same manner, Sónia, (2012) in her research conducted in Portugal found that teachers are not aware of dyslexia where they also felt powerless to provide help because they see that they are not pedagogically equipped to meet the need of their learners with dyslexia. In addition to that, Serra (2008), has also highlighted the awareness of not just teachers but also the system of education as a whole, claiming that "children with learning disabilities like dyslexia, dysgraphia, or dyscalculia are the ones we can see most in schools and which are most neglected by our educational system" (cited in Sonia, 2012, p. 43). Elias (2014) reported that secondary school teachers in New Zealand were positive in teaching learners with dyslexia because they were aware of the reading impairment but teachers did not show enough pedagogical knowledge in how to meet the need of those with dyslexia. Her study came to conclude that teachers need further training to support teachers in being wellinformed and equipped in meeting learners needs especially those with dyslexia.

Dyslexia might be a bewildering difficulty for most teachers because of system neglect and or other factors that need more research. It should be borne in mind mentioning that teacher unawareness has negative consequences for those with dyslexia where those in Algeria might not be different.

\section{3- Methods}

The present research can be expressed as mixed methods for the reason of using both quantitative and qualitative research instruments which are: questionnaire, in-depth semi-structured interviews, and focus group. I started my data collection by utilizing the web-based survey in order to familiarize my participants with the research and gather broad information regarding their knowledge of LD in general and dyslexia in particular Interviews with participants went into some depth about their awareness of learners with dyslexia and their struggle in learning English as foreign language. I could reveal their level of awareness and I also explored reasons behind their lack of understanding.. We (participants and I) also discussed extensively how teachers teach and deal with those with reading difficulties; we also spoke about tutors' interests in raising their awareness about dyslexia. The focus group discussions helped surface additional information not discussed in individual interviews and recommendations were also raised. By the end of data collection, there was a significant quantity of both statistic and narrative data that illustrated teachers' awareness of dyslexia in Algerian middle schools.

\subsection{Mixed method research}

According to Wisdom and Creswell (2013), the term "mixed methods" refers to research methodology that involves both quantitative and qualitative research 
instruments and analysis within a single investigation. The quantitative in this research is represented in the use of questionnaires and the qualitative tools are interviews and focus group. The use of interviews can be defended for its effectiveness in investigating people's awareness (Emami, \& Safipour 2013). Interviews and focus groups are also proved to be helpful when conducting research that addresses participants' awareness and understanding. Powney and Watts (2018) claimed that the interview is a good tool for educational research as it is useful to study teachers' knowledge of the classroom situation. In the same manner, Kroll et al, (2007) stated that researchers tend to use focus groups discussions to come back with answers to questions about why and how a disability is being understood (p691).

In addition to that, mixed methods can be an ideal research method to realize validity and reliability because the employment of both quantitative and qualitative research instruments can strengthen the data (Wisdom and Creswell 2013). Furthermore, mixed method has a great potential to reflect participants' points of views where one method complements the other (Creswell, and Clark 2017).

\section{3-2 Participants}

Forty two Algerian middle school teachers took part in this research investigation. Participants were contacted via e-mail to sign the consent letter with information that their participation is completely voluntary. Teachers were selected with the condition that they be current middle school EFL teachers in Algeria. The researcher, in order to avoid research bias, chose both male and female, novice and experienced teachers which could open more opportunities for different views and opinions

\section{3-3 Setting}

All four regions in Algeria were included in this research: North, South, West and East. Recruiting participants from all areas was for the purpose of giving to the research a national flavor.

\section{3-4 Procedure}

The 42 EFL teachers participated anonymously via a web-based questionnaire completed online through QuestionPro. For interviews, I traveled to different cities to interview 15 teachers from different towns and cities. My data collection ended up with two focus group discussions in Saida Algeria.

\section{4- Results}

As mentioned before, the present study aims to find out the awareness of dyslexia among EFL middle school teachers in Algeria. Based on the findings from the questionnaire, it is revealed that awareness of reading impairment among teachers is very low, as illustrated in the table below. 
Table-1. Number and percentage of EFL Teachers selecting the disability that they are familiar with (Autism, Visual motor deficit, memory, Dyslexia and Other)

\begin{tabular}{|c|c|c|c|c|c|c|c|}
\hline Answer & Count & Percent & $20 \%$ & $40 \%$ & $60 \%$ & $80 \%$ & $100 \%$ \\
\hline Autism. & 17 & $40.48 \%$ & & & & & \\
\hline Visual motor deficit. & 8 & $19.05 \%$ & 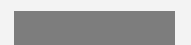 & & & & \\
\hline Memory. & 6 & $14.28 \%$ & & & & & \\
\hline Dyslexia. & 2 & $04.76 \%$ & — & & & & \\
\hline Other & 9 & $21.43 \%$ & & & & & \\
\hline Total & 42 & $100 \%$ & & & & & \\
\hline
\end{tabular}

From the above table, it is evident that teachers' awareness of dyslexia is poor. From a $100 \%$ response rate was achieved (42 responses). Seventeen EFL teachers (40.48\%) of the 42 participants reported Autism as the more familiar disability among teachers, and that presented the large size percentage of the answers, eight EFL teachers (19.05\%) stated Visual Motor Deficit and six participants (14.28\%) reported Memory as one of the difficulties they noticed withi learners. Only two EFL teachers (4.76\%) of the forty-two participants reported dyslexia and this percentage is unfortunately the lowest among teachers' answers. Finally, nine EFL teachers $(21.43 \%)$ reported other learning disabilities.

The struggle of the learners with reading impairment can be highlighted by the fact that just $4.76 \%$ of teachers are aware of dyslexia which suggests the teachers' lack of awareness and or information in the school. The percentages differences between autism and dyslexia might be a proof which evidences that teachers' knowledge about learning disorders is superficial. The British Dyslexia Association suggest that $10 \%$ of the population has dyslexia (http://www.bdadyslexia.org.uk/about), the same percentage suggested in the USA (http://www.austinlearningsolutions.com/blog/38dyslexia-facts-and-statistics.html). On the other hand, 1.1\% of the UK population has autism (http://www.autism.org.uk/about/what-is/myths-facts-stats.aspx). In the USA, $\begin{array}{llll}\text { the } & \text { figure } & 1.46 \%\end{array}$ (https://www.sciencedaily.com/releases/2016/03/160331154247.htm). One can say, therefore, that it is likely that students with dyslexia will be nine times more numerous that those with autism and yet in the questionnaire results more than $40 \%$ of teachers said they had encountered autism but less than $5 \%$ reported encountering dyslexia, despite it being $900 \%$ more common. One could conclude, therefore, that 
teachers are unaware of the symptoms of dyslexia and/or it is so hidden that they cannot identify it.

To find out whether there is any significant difference regarding teachers' awareness of dyslexia and before ending up the questionnaire, the participants were asked to add any comment concerning reading deficit and that gave teachers a chance to communicate what they would like to say about the difficulty.

Not different from the Table's result, two-thirds of teachers believed that there is lack of awareness regarding reading difficulty. Lack of awareness is including whether EFL teachers have knowledge of those with and the problems that they encounter when learning. For example, Participant (29) claimed that "teachers need awareness and they should read more about reading difficulties". Also, participant (05) pointed out "We need much more conferences and modules about that even at the universities before graduated to spread awareness among not just English teachers but also those who teach other languages." From the above Table and statements it can be understood that the vast bulk of teachers possess low level of awareness on dyslexia.

Qualitative findings from the interviews and focus groups discussions also revealed that EFL school teachers have lack of awareness of dyslexia. Themes emerged from participants' responses clearly demonstrated that there is an alarming lack of consciousness of dyslexia as shown in themes discussed below:

\section{3-1 Lack of Knowledge and Comprehension}

This theme makes it clear that Algerian EFL teachers possess poor information and understanding of dyslexia. Results from the interviewees showed that teachers have lack of necessary awareness and negligible knowledge in relation to reading difficulties. The overwhelming number of respondents argued that they do not recognize even what dyslexia means as a result of not receiving any courses and training regarding the condition. For instance, Znoubia, Ablaa, El-Arbi, Salah-Edine and Yamina claimed that "No, to be honest I don't have any idea about it,...it's very hard to answer...I am afraid to say something's that have nothing to do with dyslexia, so I don't know...Oh wow... (laughing) it is completely difficult to define it". In the same way, Batraa and Mawy just remained silent for more than 40 seconds, and in order to avoid embarrassing them, I just moved to the next question.

\section{3-2 Confusing Dyslexia Symptoms:}

Once more, this theme illustrates teachers' uncertainty which indicate lack of information as well as the bewilderment the EFL tutors have toward dyslexia in Algeria. Thus, when analysing the interviews, I have noticed again that some teachers such as Islam, Belkiss, Naiella, El-Haitham and Dorgham, confused dyslexia with other learning disabilities which has been declared in a direct manner. For example Djohaina claimed that

"Yeah, sometimes I'm just confused between dyslexia and other learning disabilities,......that's very complicated since there are a lot of difficulties........Ahhh I 
am not an expert in that, emmm may be there are too many..... I am just bewildered between Autism and dyslexia I think they have the same difficulty"

\section{3-3 Neglecting Those with Dyslexia}

According to teachers, and when they got an idea about what dyslexia is, they claimed that the difficulty is ignored and those with dyselxia are neglected. Teachers reported that the reason behind this disregard goes back to the unawareness. In this concepts, Zenoubia said that "Well, there is no clear help for the moment, and to be honest they are not providing anything they are neglected, ...emm you know when teaching a student that you don't know what he has you may misjudge him even indirectly, by neglecting him, or by thinking that he is just unmotivated to work, lazy, and that what makes maybe the teacher punishing him, or to report him to the administration where sometimes it ends with dropping out the learner. Actually, it happened so many times".

Interviewer: And since it happens so many times, in your opinion, who is the responsible?

"Maybe us as teachers because we don't know, maybe also parents, the school it's very complicated".

El-Haitham also shared the same point of view saying that "There is no help provided till now, they are actually neglected to a point where there is even no knowledge about them". In the same way, Mohamed also claimed that "In our schools there are teachers but no psychologist, no advisor and even the association of students' parents we just hear about it, no one is taking this into consideration and when the student is struggling believe me there would be no help and here the psychology of those who struggle would be in a calamity".

\section{3-4 Parents' and Teachers' Lack of Awareness:}

Findings brought some evidences which revealed that limited awareness and poor comprehension about dyslexia involves not only teachers but also parents who are may be the first who should be conscious. In this regard, Yamina: highlighted two important elements saying that "I think the majority of teachers and parents are not aware of what dyslexia is at all, they just might think that the child or the learner is just stupid, because if they know what is the problem of the learner, maybe they will treat him somehow in a special way that can suit his needs".

In the same fashion, Zenoubia: claimed also "Everybody has his own needs, but the problem if they don't know they will just classify him as an idiot, and that what might lead to psychological crises like feeling people and teachers enemies".

\section{3-5 Negative Attitude and Misunderstanding:}

Unfortunately, many EFL teachers demonstrated clear negative attitudes toward those with dyslexia, perhaps related to the unawareness. Fatima brought our attention into a 
very serious negative attitude that might occur for the reason of the lack of awareness and misunderstanding. Fatima claimed that "to be honest years ago I has a student who was saying to me Miss I can see letters moving, to be honest, I was thinking him mocking me or trying to be funny, I never gave attention to that, I never said that he may get a problem, and once a teacher of Arabic she said to me the same thing and I've said to her don't believe him he is just trying to create some excuses to not learn....she kept silent".

El-haithem gave a clear reason for the negative attitude and the misunderstanding that EFL teachers may have toward those with dyslexia. He claimed that "I told you we have not been aware of those with dyslexia, so we were doing nothing about that, we were just treating them like any student, but now and since we are informed of such cases we try to come up with some solutions in order to provide help". From this argument, we can understand that teachers' negative attitude may go back to their lack of awareness to the condition dyslexia as well as the poor training that they receive regarding this point.

It was clear that from teachers answers that having insufficient awareness could result in misjudging and negative attitudes towards those with dyslexia, such as seeing them as stupid, lazy, unmotivated, mocking them and or reporting them to the administration where it sometimes ends up with the learner dropping out. This miscomprehension and these negative attitudes might lead to other complexities such as poor performance and less academic success. Perhaps teachers did not find it necessary to be acquainted with proper knowledge on dyslexia or may be as it is not a physical disability that it can't be easily recognised.

\section{5- Discussion}

The study's objectives as mentioned before were to assess EFL teachers' awareness to dyslexia and to explore their understanding to those with the condition. The present findings show that dyslexia is a difficulty which is not familiar among the overwhelming majority of teachers, even though the literature has stressed the importance of teachers' awareness in students success rather than being misconceived and or humiliated (Wadlington and Wadlington 2005; Elias 2014), and unfortunately teachers in Algeria are still unacquainted with the meaning of dyslexia. Most Middle school teachers who participated in this study (40 out of 42) reported that they have never heard about reading impairment. These findings mirrored Fekih (2018) view who claimed that teachers in Algeria need to be aware of dyslexia in order to understand the struggle of affected learners. Furthermore, the majority of teachers considered that the educational support received by teachers is not adequate; many teachers viewed that dyslexia is neglected in the Algerian education system where there is no help provided to accommodate students needs. Hence, as claimed in the literature these issues hamper teachers from teaching those with dyslexia according to their needs (Kataoka et al., 2004).

Results showed the urgent need for increasing teachers' knowledge of dyslexia by giving importance to teacher training as well as national conferences and workshops 
that bear the responsibility of raising teachers' awareness, and inform them with the essential guidance. This point goes hand in hand with Sónia, (2012) study which proved that teachers are ill-equipped and not aware of dyslexia because they were neither informed nor trained on how to teach learners with reading impairment. Teachers raised another element of paramount significant which is the role of the psychologist to increase learners' self-esteem and motivation in both theoretical and practical sides. The lack of psychologists can be evidenced in teachers' negative attitudes toward those with dyslexia; teachers frequently misconceive learners' underachievement by seeing them as lazy, unmotivated and or stupid (Smart, 2011 p.290). Unfortunately, the opinions of EFL teachers and their lack of awareness in this study reinforce these views in the literature. Even though the majority of teachers agreed that those with dyslexia have the right to study along with their peers, teachers were troubled that it would be difficult as they are not knowledgeable enough in providing assistance to those with dyslexia. According to teachers the actual educational problems such as class size could be an obstacle and besides lack of appropriate techniques might be a reason for being neglected. Serra (2008), clearly in her research also brought evidence that those with dyslexia, dysgraphia, and dyscalculia are often neglected and the situation in Algeria is not different. Additionally, what's adding insult to injury is that this lack of awareness, linked to teachers' negative attitudes, is reported as having impacted harmfully on learners' psychology to the point where they see teachers as enemies. This urgently calls for more research in Algeria emphasizing the relationship between those with dyslexia and their teachers in the classroom settings.

It is also clear that the success of any learner, whether or not with special needs, requires qualified teachers who are aware well-prepared to meet the need of every student. Elias (2014) claimed teachers in New Zealand were open and happy to teach learners with dyslexia simply because they are knowledgeable about what does it mean to be dyslexic. These findings can illustrate how Algerian teachers started being concerned with those with reading impairment, and that can clearly give an idea that awareness itself can change teachers' attitude to be positive toward those with the difficulty. Teachers brought to light a very important point which is parents' awareness. According to teachers they might be also unaware of their children disabilities which in turn might make it more complicated for teachers to understand their learners' needs and struggle. Kafia, (2014) underlined that in order to ensure the students' success then both parents' and teachers' awareness is required because it is a key factor in the accomplishment of inclusive education. The issue of parents' awareness may higlight the need for further research to explore their understanding.

Algerian EFL teachers are not at the required level for the time being although the literature indicates that awareness is if paramount significance to accommodate those with dyslexia and help them succeed (Elias, 2014; Kafia, 2014). There is no doubt that EFL teachers are doing their best to educate and teach, but this is still insufficient if teachers lack the necessary awareness than those with dyslexia and other learning disabilities may continue struggling. 


\section{6- Conclusion and Recommendations}

The investigation revealed that Middle school EFL teachers in Algeria have a low level of awareness of dyslexia, and maybe other learning difficulties that need more research. From the study, teachers expressed their lack of knowledge, understanding as well as their confusion of disabilities and they are misconceiving those who are struggling with LD. Nearly all teachers showed sympathy and a desire to accommodate the different needs of the children with dyslexia and other difficulties despite the actual educational challenges in Algeria. Participants also showed a great interest in knowing more about dyslexia and the appropriate methods and techniques to help them overcome their difficulties and realizing integration. Based on participants' views, we can conclude that EFL teachers are willing to provide help to those with dyslexia. In addition to that, and with longitudinal monitoring on the reality of the level of Algerian teachers' awareness and understanding, and by increasing teachers' support, awareness sessions, and training, in the light of this emerging evidence, then EFL teachers and other tutors may be capable of helping learners with learning difficulties, specifically dyslexia.

Based on EFL teachers' recommendations in the present study, the following implications are put forth for enhancing education and raising awareness. Participants strongly emphasized on the need for improving their awareness of dyslexia and other related learning difficulties. Teachers addressed the need for workshops and educational seminars to speak about dyslexia, its features, and indicators for more understanding. Teachers also asked to be informed about the characteristics of those with reading impairment and where their difficulties have to be taught to every teacher either novice or experienced one. Teachers strongly asked to be equipped with appropriate guidance, technique, and strategies to teach affected learners. Some participants highlighted the importance of diagnosis, and subsequent support, arguing that teachers' raised awareness itself cannot be the determining factor in providing help. Teachers believe that, through early assessment, the need of the learners will be specifically underlined and that what help teachers respond to the learners' interests where guidance can facilitate the process of accommodating and addressing the difficulties.

In addition to that, teachers advocated encouraging existing specific consultants that can assist psychologically those with special needs where this has to be an inseparable part of the school policy and departments. EFL teachers also proposed appropriate curriculum which is designed to meet the need of both those with difficulties and typical learners as well and in order to achieve this point I suggest that teachers who are teaching learners with special needs should arrange academic meetings with program designer educational policy maker planners and authorities for the purpose of discussing the weak points in the curriculum suggesting approaches to improve the quality of eructation because I believe that educating learners with LD is the responsibility of all and not just teachers.

\section{Reference}


[1] American Academy of Pediatrics. (2009). Joint statement: Learning disabilities, dyslexia, and Vision. Pediatrics, 124(2), 837-844; DS1-DS4. Available: http://pediatrics.aappublications.org/content/pediatrics/124/2/837.full.pdf

[2] Bartlett, D., Moody, S. and Kindersley, K., (2010). Dyslexia in the Workplace: an Introductory Guide. John Wiley \& Sons.

[3] Buckler, S. and Castle, P. (2014) Psychology for Teachers. United Kingdom: SAGE Publications.

[4] Campbell, J., Gilmore, L. and Cuskelly, M., (2003). "Changing student teachers' attitudes towards disability and inclusion." Journal of Intellectual and Developmental Disability, vol. 28(4), pp. 369-379.

[5] Christo, C., Davis, J.M. and Brock, S.E., (2009). Identifying, Assessing, and Treating Dyslexia at School. Springer Science \& Business Media.

[6] Creswell, J. W., \& Clark, V. L. P. (2017). Designing and Conducting Mixed Methods Research. Sage publications.

[7] Elias, R. (2014). Dyslexic learners: An investigation into the attitudes and knowledge of secondary school teachers in New Zealand. Unpublished Master Dissertation, University.

[8] Emami, A., \& Safipour, J. (2013). "Constructing a questionnaire for assessment of awareness and acceptance of diversity in healthcare institutions." BMC health services research, vol. 13(1), p. 145.

[9] Endlsey, M.R. (1995). "Toward a theory of situation awareness within dynamic systems." Human Factors Journal, vol. 37(1), pp. 32-64.

[10] Fekih, M. (2018). "We need to challenge the lack of awareness surrounding dyslexia in EFL schools in Algeria". Dyslexia Voice, Summer, pp. 12-13.

[11] Frith, U., 1999. "Paradoxes in the definition of dyslexia." Dyslexia, vol. 5(4), pp. 192-214.

[12] Gibson, S. and Kendall, L. (2010). "Stories from school: dyslexia and learners' voices on factors impacting on achievement." Support for Learning. vol. 25(4), pp.187-193.

[13] Gilchrist, P., (1997). Dyslexia: a Multidisciplinary Approach, Nelson Thornes.

[14] Kafia, E. (2014). "Teachers and parents awareness-a key factor to success of inclusive education," European Scientific Journal, ESJ, vol. 10(28), pp. 327-335.

[15] Karande, S., Mahajan, V. and Kulkarni, M., (2009). "Recollections of learning-disabled adolescents of their schooling experiences: A qualitative study," Indian Journal of Medical Sciences, vol. 63(9), pp. 382-391.

[16] Kataoka, M., Van Kraayenoord, C.E. and Elkins, J., (2004). "Principals' and teachers' perceptions of learning disabilities: A study from Nara prefecture", Japan. Learning Disability Quarterly, vol. 27(3), pp. 161-175. 
[17] Kenny, M., McNeeba, E., Shevlin, M. and Daly, T. (2000) Hiden Voices, Young People with Disabilities Speak About Their Second Level Schooling, Cork: South West Regional Authority.

[18] Knight, C., 2018. "What is dyslexia? An exploration of the relationship between teachers' understandings of dyslexia and their training experiences." Dyslexia, vol. 24(3), pp. 207-219.

[19] Kroll, T., Barbour, R., \& Harris, J. (2007). Using focus groups in disability research. Qualitative Health Research, 17(5), 690-698.

[20] Lyon, G.R., Shaywitz, S.E. and Shaywitz, B.A., (2003). "A definition of dyslexia." Annals of dyslexia, vol. 53(1), pp. 1-14.

[21] Menon, K. P. (2016). Awareness on learning disabilities among elementary school teachers. Asian Journal of Education and Training, vol. 2(2), pp. 78-83.

[22] Miles, E., (1995.) "Can there be a single definition of dyslexia?." Dyslexia, vol. 1(1), pp. 37-45.

[23] Nicolson, R.I. and Fawcett, A., (2010). Dyslexia, learning, and the brain. MIT press.

[24] Powney, J., \& Watts, M. (2018). Interviewing in educational research. Routledge.

[25] Pumfrey, P.D. and Reason, R. (2013). Specific learning difficulties (dyslexia): Challenges and responses, United Kingdom: Routledge.

[26] Shaywitz, S.E. and Shaywitz, B.A., (2013). "Making a hidden disability visible: What has been learned from the neurobiological studies of dyslexia," Handbook of Learning Disabilities, pp. 643-657.

[27] Smart, J., (2011). Disability across the developmental life span: For the rehabilitation counselor. Springer publishing company.

[28] Sónia, L., (2012). "Dyslexia through the eyes of primary school teachers," Procedia-Social and Behavioral Sciences, vol. 69, pp. 41-46.

[29] Townend, J. and Turner, M., (2000). Dyslexia in practice. A Guide for teachers. The Dyslexia Institute Strain. United Kingdom.

[30] Wadlington, E., Jacob, S. and Bailey, S., (1996). "Teaching students with dyslexia in the regular classroom," Childhood Education, vol. 73(1), pp. 2-5.

[31] Wadlington, E.M. and Wadlington, P.L., (2005). "What educators really believe about dyslexia," Reading Improvement, vol. 42(1), pp. 16-33.

[32] Wisdom, J., \& Creswell, J. W. (2013). Mixed methods: integrating quantitative and qualitative data collection and analysis while studying patientcentered medical home models. Rockville: Agency for Healthcare Research and Quality. 
[33] Wormald, C. (2015). Intellectually gifted students often have learning disabilities. Faculty of Social Sciences - Papers [online]. pp. 1-3. Available: https://ro.uow.edu.au/sspapers/1413/ 